\title{
Some Notes on Phonological Phrasing in Brazilian Portuguese*
}

\author{
(Algumas Observações sobre a Formação de Sintagmas Fonológicos \\ no Português Brasileiro)
}

\author{
Filomena SANDALO \& Hubert TRUCKENBRODT \\ (Unicamp \& Universität Tübingen)
}

\begin{abstract}
In this paper, we argue that phonological phrasing in Brazilian Portuguese is determined by the interaction of right-alignment of syntactic and phonological phrases (Selkirk 1986) and a eurythmic factor of Uniformity (Ghini 1993), which prefers pphrases of equal prosodic length. The Uniformity requirement shows some unexpected properties. It is not tied to a preferred length of p-phrases, and it appears to be restricted to p-phrases overlapping with the subject and the verb of the clause.
\end{abstract}

KEY-WORDs: Prosodic phonology; Stress retraction; Intonation; Phonology-syntax interface.

RESUMO: Neste artigo, argumentamos que a formação de sintagmas fonológicos no português brasileiro é determinado pela interação de uma restrição de alinhamento à direita entre sintagmas fonológicos e sintáticos (Selkirk 1986) e de um fator eurítmico de Uniformidade (Ghini 1993), o qual prefere sintagmas fonológicos de tamanhos prosódicos idênticos. O princípio de uniformidade apresenta algumas propriedades não

\footnotetext{
* Many thanks to our consultants Paulo de Sá Porto, Maria Bernadete Abaurre, Marcelo Barra Ferreira, Giovana Hirae, Luciani Tenani, and Maria Luiza Abaurre for their time and patience with the list of sentences (for some of them growing in size) we asked them to judge. We also thank FAPESP (Fundação de Amparo à Pesquisa do Estado de São Paulo, Brazil) for financial support under the grants 2001/00529-4, 98/01831-1, and 98/3382-0, and and FAEP (Fundação de Apoio ao Ensino e Pesquisa, Universidade Estadual de Campinas, Brazil) for the grant 1242/00. Finally, we express a special thanks to Maria Bernadete Abaurre for various comments and suggestions and for the discussion of our methodology of data elicitation. All remaining errors are of course our own. The names of the authors are arranged in alphabetical order. A slightly different version of this paper has been published in the MIT Working Papers in Linguistics 42, 2002.
}

D.E.L.T.A., 19:1, $2003(1-30)$ 
esperadas, uma vez que não é restrito a um tamanho ideal de sintagmas fornológicos, e parece estar restrito aos sintagmas fonológicos que equivalem ao sujeito e ao verbo de uma dada sentença

PALAVRAS-CHAVE: Fonologia prosódica; Retração de acento; Entoação, Interface sintaxe-fonologia.

\section{Introduction: Phonological Phrases in Brazilian Portuguese}

In this paper, we describe some initial results concerning phonological phrasing in Brazilian Portuguese (BP).

Evidence for phonological phrasing in $\mathrm{BP}$ comes from stress retraction under stress clash (Abousalh 1997) and from intonation (Frota and Vigário 2000a, b). This paper focuses on the phenomenon of stress retraction. The phenomenon is comparable to the English rhythm-rule (Liberman and Prince 1977, Hayes 1989) or stress retraction in standard northern Italian (Nespor and Vogel 1979, 1986, 1989). For example, in BP, café, 'coffee', has final stress in isolation, here marked by underlining (the accent mark is orthographic). When followed by a word with initial stress, such as quente, 'bot', the word café does not retain its final stress, but retracts it to the left: café quente, 'hot coffee'. This judgements, like the other judgements on stress retraction reported in this paper, hold of a normal rate of speech in sentences that convey new information, as in headline news. Slow, deliberate speech leads to additional p-phrase edges and may thus block retraction that otherwise occurs. Retraction on any element can also be blocked by what intuitively feels like special emphasis on an element: The emphasized element will not then tolerate stress retraction. We return to the special emphasis in the section on focus at the end of the paper. ${ }^{1}$

\footnotetext{
1 The new information reading of sentences as a whole in our corpus is guaranteed by asking our consultants to judge whether retraction is or is not allowed if the sentences were read as newspaper headlines. This is important because, if focus or emphasis blocks retraction, topicalization of old information forces retraction to occur where otherwise it does not. We add a note on our elicitation technique here. Three consultants were interviewed in person by one of the writers of this paper, while two other consultants were consulted via e-mail, and one consultant underwent both types of tests. The consultations via e-mail were intended to ensure that the presence of a researcher did not interfere with the judgements. Importantly, the judgements converged across the two methods of elicitation. The elicitation of the sentences as new information (newspaper headline) was crucial
} 
A variety of other languages have also been shown to exhibit one or another version of this phenomenon, among them Catalan (Nespor and Vogel 1989), Dutch (Visch 1989), Greek (Nespor and Vogel 1989), Polish (Hayes and Pupple 1985), and Turkish (Nespor 1990). European Portuguese, incidentally, does not shift stress in response to stress-clash (Frota 1998). In Brazilian Portuguese, the phenomenon was first noticed by Major 1985, and discussed in more detail in Abousalh 1997, who noticed that it is conditioned by the phonological phrase. ${ }^{2}$

As in Italian (Nespor and Vogel 1986, 1989) and English (Hayes 1989), retraction does not take place where the two words are separated by the boundary of a phonological phrase (p-phrase or $P$ in the following). We will show below that such a p-phrase boundary is regularly assigned between subject and verb in BP. Accordingly, there is no retraction in $(\text { café })_{P}\left(\right.$ queima $_{P}$,

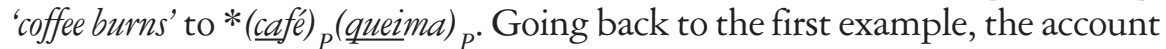
is coherent if no p-phrase boundary is assigned internal to the NP there: (café quente) ${ }_{P}$, 'bot coffee'.

Of subordinate interest in the present paper are the questions of what triggers stress retraction and how the change is formally represented. Since Liberman and Prince 1977, it is usually assumed that stress retraction is triggered by stress clash. In English, it has been argued that the possibility of placing a pitch-accent early in the utterance may additionally trigger

in that, early in the elicitation process, one consultant was not thus instructed during a personal elicitation, and reported judgements that did not converge with the judgements of the other speakers reported in this paper. Two consultants were consulted more than once in order to test for internal consistency. The judgements were consistent across the two occasions. Note that our corpus manipulates two-syllable words in the retraction environment in order to guarantee that in case of stress clash, stress retraction would be the preferred remedy. Also in Santos 2001 bisyllabic words were selected to guarantee that retraction would be the preferred option to undo stress clashes. For other ways to undo stress clashes see Abousalh (1997). Stressed high vowels were avoided in our corpus because of an apparent tendency not to retract from a high vowel in BP for

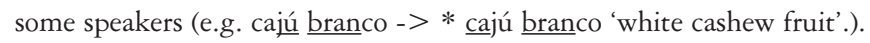

2 Abousalh, on the basis of production data, shows that, although cases of stress clash were not abundant in her data, it was possible to notice that clashes were never undone when they occurred at the boundary of phonological phrases. Furthermore, the only cases of stress retraction under stress clash that did occur in her corpus were inside a phonological phrase. The data analyzed by Abousalh correspond to passages from the bible recorded from a catholic mass (first and second readings) broadcast by the TVE television network, Rio de Janeiro, Brazil. This type of data was selected because it presents a formal variety of spoken Brazilian Portuguese with different rates of speech. 
stress retraction in the absence of a stress clash (see Hayes 1984, ShattuckHufnagel et al. 1994 and references there). We have not so far found a similar effect in BP. Abousalh's data was transcribed taking pitch in consideration and this data suggest that pitch variation plays no role in triggering stress retraction in BP.

Hayes 1984 also argues for a number of eurythmic principles in an investigation of English. A different theory for English is defended in Gussenhoven (1991), where the phenomenon is formalized in terms of the cyclic elimination of an accent surrounded by two other accents.

Liberman and Prince (1977) and Hayes (1984) argue for a formalization of the rhythm rule in English in terms of a reversal of the strong-weak relations in a metrical tree. Nespor and Vogel (1989) argue with regard to stress retraction in Italian and other languages for a formalization in terms of beat addition and beat deletion in a metrical grid, in response to constraints against clashes and lapses.

An issue that we will return to below is why the p-phrase boundary affects the application of stress retraction. The most straightforward assumption, namely that stress clash is constituted only within p-phrases, was made by Nespor and Vogel (1986). It was later argued against in the more detailed investigation in Nespor and Vogel (1989) (see also Nespor (1999)). In the theory of Nespor and Vogel (1989), phrasal prosodic domains such as the p-phrase are domains of stress-assignment. ${ }^{3}$ Nespor and Vogel (1989) argue that adjacent word-stress constitutes a stress clash regardless of p-phrases, and that the remedy of stress-clash-beat deletion and addition resulting in apparent retraction-is blocked by the presence of $\mathrm{p}$-phrase stress in the final position of the p-phrase. We illustrating this with our BP example and indicate p-phrase stress by double underlining. Retraction is possible on the word-stress in (café quente) ${ }_{P}$, but it is blocked by the additional presence of $\mathrm{p}$-phrase stress in (café $)_{P}$ (queima) $_{P}$. In this theory, the intervening p-phrase boundary between the two elements conditions retraction indirectly, by forcing the assignment of p-phrase stress on the potential target of the retraction. We take this theory as a starting point for BP.

\footnotetext{
3 See also Hayes and Lahiri (1991) for a similar assumptions in Bengali, and Hsiao 2001 for arguments to this effect in Taiwanese.
} 
In the more complex syntactic structure in (1) in BP, we can establish the phrasing indicated there: The noun and the adjective of the subject form a p-phrase together, the verb and the short object are phrased together, and a final adverbial is phrased separately. Evidence for this assignment of prosodic structure is shown in (2): The application of stress retraction in (2a) and (2c) gives evidence for the absence of p-phrase edges between $\mathrm{N}$ and $\mathrm{A}$ and between $\mathrm{V}$ and $\mathrm{N}$. At the same time, the inapplicability of stress retraction in $(2 \mathrm{~b})$ and $(2 \mathrm{~d})$ provide evidence for the p-phrase boundaries between the subject and the verb, and between the object and the final adverbial. ${ }^{4}$

$$
\begin{aligned}
& \text { (1) }\left(\begin{array}{llll} 
& \mathrm{x})_{\mathrm{P}} & (\mathrm{x})_{\mathrm{P}} & (\mathrm{x})_{\mathrm{P}}
\end{array}\right. \\
& {[(\text { DET }) \mathrm{N} \quad \mathrm{X}]_{\mathrm{NP}} \quad \mathrm{V} \quad[\text { (POSS) } \mathrm{N}]_{\mathrm{NP}} \quad[\mathrm{Adv}]_{\mathrm{AdvP}}} \\
& \text { (2) a. ( N_A ... } \\
& O \text { café quente queimou a boca ontem. cf. café } \\
& \text { the coffee hot burned the mouth yesterday } \\
& \text { 'The hot coffee burned my mouth yesterday.' } \\
& { }^{\text {Um chinês }}{ }^{\mathrm{N}_{1} \mathrm{~A}} \quad{ }^{\cdots} \text { louco cantou samba ontem. cf. chinês } \\
& \text { a Chinese-person crazy sang samba yesterday } \\
& \text { 'A crazy Chinese person sang samba yesterday.' } \\
& \text { ( } \mathrm{N}_{=} \mathrm{N} \quad \ldots \\
& \text { Losé Carlos comeu maçãs ontem. cf. José } \\
& \text { 'José Carlos ate apples yesterday.' } \\
& \text { b. ( } \mathrm{N} \quad \mathrm{A} \quad \underline{\mathrm{V}} \quad \ldots \\
& \text { Um frango chinês queimou minha boca ontem. } \\
& \text { * chinês queimou } \\
& \text { a chicken Chinese burned my mouth yesterday } \\
& \text { 'A Chinese chicken burned my mouth yesterday.' }
\end{aligned}
$$

similarly in:

\footnotetext{
4 Two of our consultants generally did not accept stress retraction in the word chinês 'Chinese'. One of these speakers, however, reported that the stress retraction in um chinês louco cantou samba ontem (2a) is much better than in um frango chinês queimou minha boca ontem in (2b). That is, (2a) was assigned by a question marker whereas ( $2 \mathrm{~b}$ ) was ruled out. The resistence to stress retraction for a subset of the speakers in a word like chinês might be related to the quantity sensitive nature of BP stress assignment, and to the heaviness of the closed second syllable of chinês. For a discussion of BP primary stress assignment see Bisol (1992).
} 


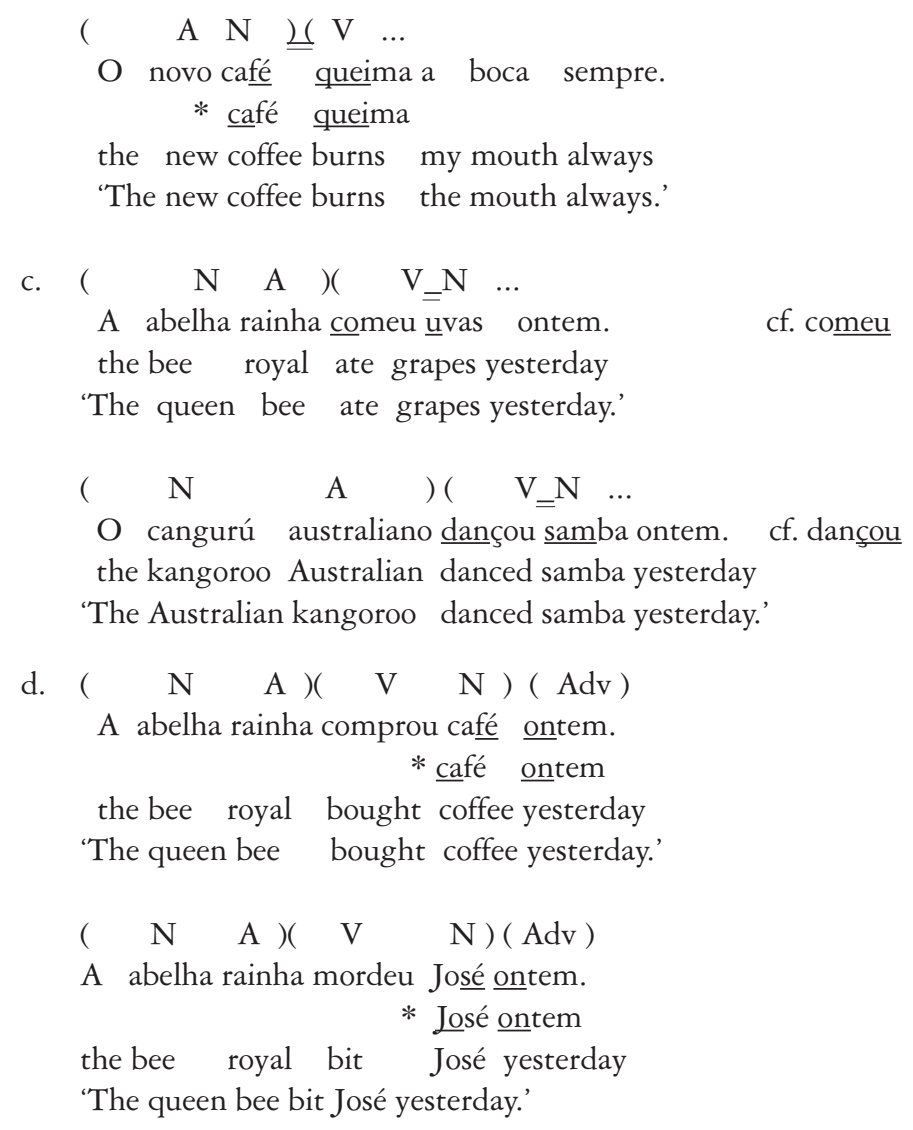

The presence of $\mathrm{p}$-phrase prominence is to some extent accessible to nativespeaker intuitions in BP, independent of the evidence for it due to stressretraction in particular instances. In part, these intuitions seem to stem from the assignment and scaling of tones in the intonational system of BP, to which we briefly return below. Frota and Vigário 2000b show that $94 \%$ of the p-phrases in a corpus of 20 sentences were assigned a tonal event. (In European Portuguese, in contrast, only $27 \%$ of the p-phrases held a tonal event when the same corpus was analyzed.) These intuitions support the phrasings derived in this paper. In (2), for example, intuitions about stress and intonation support the result that the examples in (2a.-d.) are generally phrased and stressed as in (1).

We find that stress retraction provides a reasonably clear way of pinning down the p-phrases, as this phenomenon makes the presence vs. absence 
of p-phrase edges emerge in judgements of preference between the retracted and the unretracted forms. We thus rely on judgements about stress retraction of six speakers of BP Southeast Brazil not including the authors. The first author also is a native speaker of this dialect of BP, and her intuitions support the phrasal stress and the intonational patterns that accompany our conclusions from our data on stress retraction.

How, then, are p-phrases assigned in BP? Across languages, p-phrase are related to syntactic phrases to a certain extent. At the same time, focus, eurythmic and length-effects may enter into the formation of $\mathrm{p}$ phrases, obscuring the relation to syntax to a larger or smaller extent, depending on the language. In BP, syntax, focus, and eurythmy all seem to enter into the formation of $\mathrm{p}$-phrases. In section 2 we discuss the main effect of syntax on p-phrases. In section 3 we address an interesting eurythmic effect in the phrasing of BP, and in section 4 we demonstrate a syntactic restriction on the eurythmic effect. In section 5 we briefly shows an effect of focus on the prosodic patterns and its interaction with eurythmy. The results are summed up in section 6 .

\section{The Main Effect of Syntax}

We derive the phrasing in (1) by the constraint in (3) that right-aligns edges of lexical syntactic XPs with edges of p-phrases. Right-alignment of this kind was originally argued for by Chen (1987) for Xiamen Chinese, and generalized by Selkirk (1986) to a universal theory of the syntaxphonology mapping, with special attention to phrasal right-edge alignment in Chi Mwi:ni. Left-alignment of syntactic XPs with p-phrases has been postulated for other languages including Shanghai Chinese (Selkirk and Shen 1990) and Japanese (Selkirk and Tateishi 1991). De Lacy (1999) argues that phrasing in Maori shows the simultaneous effects of left- and right-alignment. ${ }^{5}$

\footnotetext{
5 The theory was later formulated in Optimality Theory (Prince and Smolensky 1993) in Selkirk (1995), where the notion of edge-alignment from Selkirk (1986) had independently been expanded in the theory of Generalized Alignment (McCarthy and Prince 1993). Truckenbrodt (1995, 1999) supports the claim that phrasal edge-alignment is a ranked and violable constraint in the grammar by showing how its effect may be suppressed by another syntax-prosody mapping constraint (Wrap$\mathrm{XP}$ ) in some languages, though in ways that still allow for the detection of the effects of the suppressed Align-XP in special cases.
} 
(3) Align-XP,R: The right edge of each lexical XP coincides with the right edge of a p-phrase.

Align-XP,R derives the phrasing in (1) by requiring edges of $\mathrm{p}$-phrases at the right edge of the subject NP, at the right edge of the object NP, and at the right edge of the adverbial phrase. This results in the attested subdivision of this example. No p-phrase edges are assigned between $\mathrm{N}$ and $\mathrm{A}$ within the subject, and between the verb and its object-these junctures do not coincide with the right edges of syntactic XPs.

Given only the structure in (1) above, one might alternatively hypothesize that BP phrases a string by grouping sets of two prosodic words into a phonological phrase from left to right. However, a p-phrase boundary to the right of a lexical XP is regularly found in BP, regardless of the number of words in a p-phrase. Thus, (4) shows the presence of a pphrase boundary between a subject and a verb with no object. Here an algorithm in terms of grouping of two with no reference to syntax would wrongly group the subject and the verb together, while edge-alignment correctly predicts the separate phrasing.

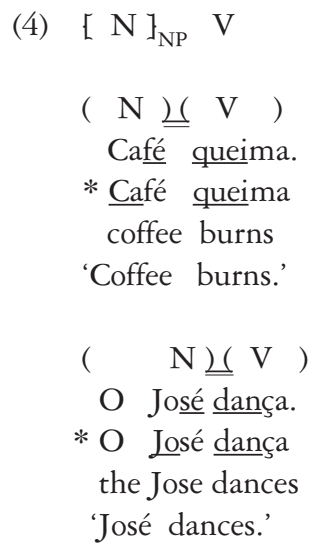

(5) and (6) are examples of a subject and a VP with different prosodic length, $1+2$ prosodic words in (5) and $2+1$ in (6). The impossibility of stress retraction between subject and verb here is evidence of the p-phrase boundary between subject and verb in both cases. (We will show below, however, that the complete phrasing of these cases is also subject to a eurythmic factor that adds an additional p-phrase boundary in each of these cases). 


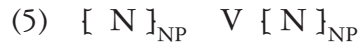

$(\mathrm{N}) \underline{(\mathrm{V}}$

Café queima a boca.

* Café queima

coffee burns the mouth

'Coffee burns the mouth.'

$(\mathrm{N}) \underline{(\mathrm{V}}$

José come uvas.

* Losé come

José eats grapes

'Joe eats grapes.'

(6) $\left[\begin{array}{lll}{[} & \mathrm{N} & \mathrm{A}\end{array}\right]_{\mathrm{NP}} \mathrm{V}$

$\mathrm{N} \quad \mathrm{A} \underline{\underline{(}} \mathrm{V})$

O cavalo chinês corre.

* chinês corre

the horse Chinese runs

'The Chinese horse runs.'

similarly in:
A $\quad \mathrm{N} \underline{(\mathrm{V})}$
$\mathrm{O}$ novo café queima.
* café queima
the new coffee burns
'The new coffee burns.'

For completeness, (7) shows a case of phrasing with a binary subject followed by a verb and an object. Stress-retraction gives evidence for a pphrase boundary between subject and verb, predicted on either of the alternatives considered so far.

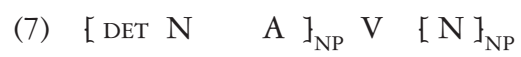

$$
\mathrm{N} \quad \mathrm{A} \underline{\underline{(} \mathrm{V}}
$$

O cavalo chinês come uvas.

* chinês come

the horse Chinese eats grapes

'The Chinese horse eats grapes.' 
similarly in:

$$
\begin{aligned}
& \text { A } \mathrm{N})(\mathrm{V} \\
& \text { O novo café } \\
& \text { *afé queima a boca. } \\
& \text { the new coffee burns the mouth } \\
& \text { 'The new coffee burns the mouth.' }
\end{aligned}
$$

Further evidence for right-alignment of syntactic and phonological phrases comes from adverbial phrases. In (8), an adverbial phrase intervenes between subject and verb. In (9), the adverbial phrase separates the verb and its object. In both cases, a p-phrase boundary demarcates the right edge of the adverbial phrase, as predicted by Align-XP,R. For (8), this would be unexpected on the hypothesis that groups prosodic words together in sequences of two-the adverb and the following verb would then fall within the same p-phrase in this example.

(8)

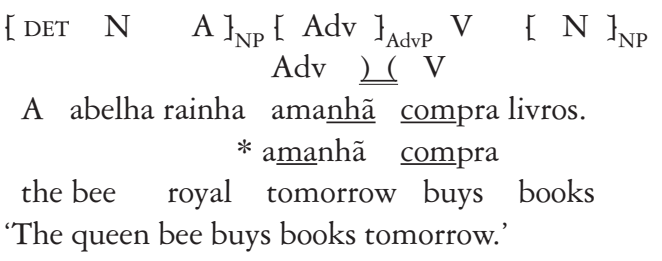

(9) $\left[\begin{array}{llll}\mathrm{DET} & \mathrm{N} & \mathrm{A}\end{array}\right]_{\mathrm{NP}} \mathrm{V} \quad[\mathrm{Adv}]_{\mathrm{AdvP}}[\mathrm{N}]_{\mathrm{NP}}$ A abelha rainha comerá amanhã unvas. * amanhã uvas the bee royal will-eat tomorrow grapes 'The queen bee will eat grapes tomorrow.'

A note on the syntax of BP: The fact that an adverb can intervene between the verb and its object as in (9) suggests that the verb has moved from its base-position next to the object to a higher functional projection. The adverb in (9) might then be left-adjoined to VP, where it follows the 
moved verb (Costa 1998: 19-36). ${ }^{6}$ This scenario does not affect the cases derived so far: The right edge of the verb itself, not being phrasal in nature, does not invoke Align-XP,R. At the same time, the right edge of the VP is irrelevant to the phrasings considered here: The right edge of VP is trivially right-aligned with a p-phrase, coinciding either with the right edge of the object or with the right edge of the utterance in the examples in this paper.

\section{A Eurythmic Effect: Uniformity}

We turn to an interesting eurythmic effect that can be observed in our BP data. We establish the application of such an effect in this section, and will show a syntactic restriction on it in section 4 .

Consider first (10), phrased as predicted by Align-XP,R, and with no influence of the eurythmic effect. (7) above gave evidence of the pphrase boundary between subject and VP in such structures. In (10), stress retraction gives evidence for the joint phrasing of $\mathrm{N}$ and $\mathrm{A}$ within the subject.

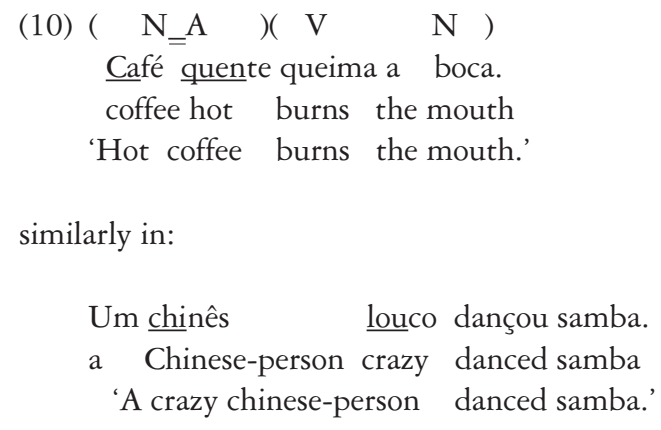

Consider then (11), minimally different from (10) in not having an object to the verb. Though this difference in the presence of overt material is located in the VP, it non-locally affects the phrasing of the complex

6 Costa (1998) argues for European Portuguese that the verb undergoes short distance movement to $\mathrm{AgrO} / v$. In the resulting structure, an adverb may separate the verb and the object. Since his data and the BP data concerning this specific phenomena are comparable, Costa's analysis might plausibly extend to BP. 
subject: In (11), unlike in (10), the $\mathrm{N}$ and $\mathrm{A}$ within the subject are phrased separately, as evidenced by the near-impossibility of stress retraction in this case. ${ }^{7}$

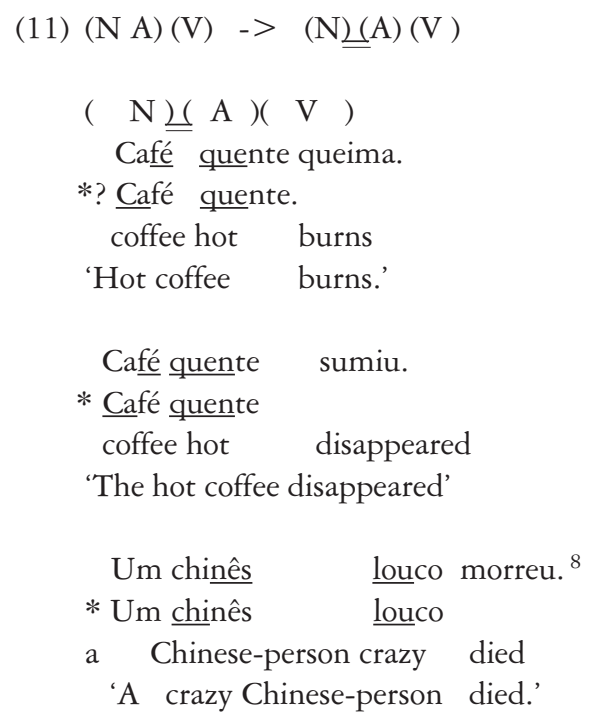

We hypothesize that this is due to a eurythmic factor of Uniformity that favors p-phrases of equal length. Uniformity allows the uniform phrasing of $2+2$ prosodic words, but turns the non-uniform phrasing $2+1$ and $1+2$ into the uniform phrasing of $1+1+1$. In (11), and in later examples exhibiting Uniformity effects, we highlight this effect by

\footnotetext{
All the consultants, while accepting the non-retracted version, were unsure about ruling out the retracted version of the sentence café quente queima 'hot coffee burns'. They assigned the symbol *?, whereas they systematically ruled out the other sentences in (11). An explanation for this fact is offered in Santos 2002. Santos argues that stress retraction is sensitive to the transitivity of a verb. According to Galves (1989), BP accepts the empty category pro in object position, and Santos compares truly intransitive verbs with verbs that have pro as the internal argument. The author concludes that they show different behavior for stress retraction under clash. Note that the verb in café quente queima 'hot coffee burns' is ambiguous in that it can be understood as a transitive verb whose internal argument is pro. Note also that the other sentences in (11) have a truly intransitive verb and these sentences were systematically ruled out by all of our consultants.

8 As mentioned before, one of our consultants reports to prefer avoiding stress retraction in the word chinês. Note that again even this native speaker of BP reported that the retraction in um chinês louco morreu 'a crazy chinese-person died' is much worse than in um chinês louco dançou samba 'a crazy chinese-person danced samba.'
} 
schematically showing the phrasing predicted by Align-XP,R alone as well as the attested phrasing as changed by Uniformity.

Just as the length of the VP can non-locally affect the phrasing of a complex subject in (10) and (11), so the length of the subject can also nonlocally affect the phrasing of a complex VP, as shown in the contrast between (12) and (13). (12) establishes the joint phrasing of a verb and its object, in the presence of a binary subject. In (13), on the other hand, where the subject consists of a single prosodic word, the verb and object are phrased separately..

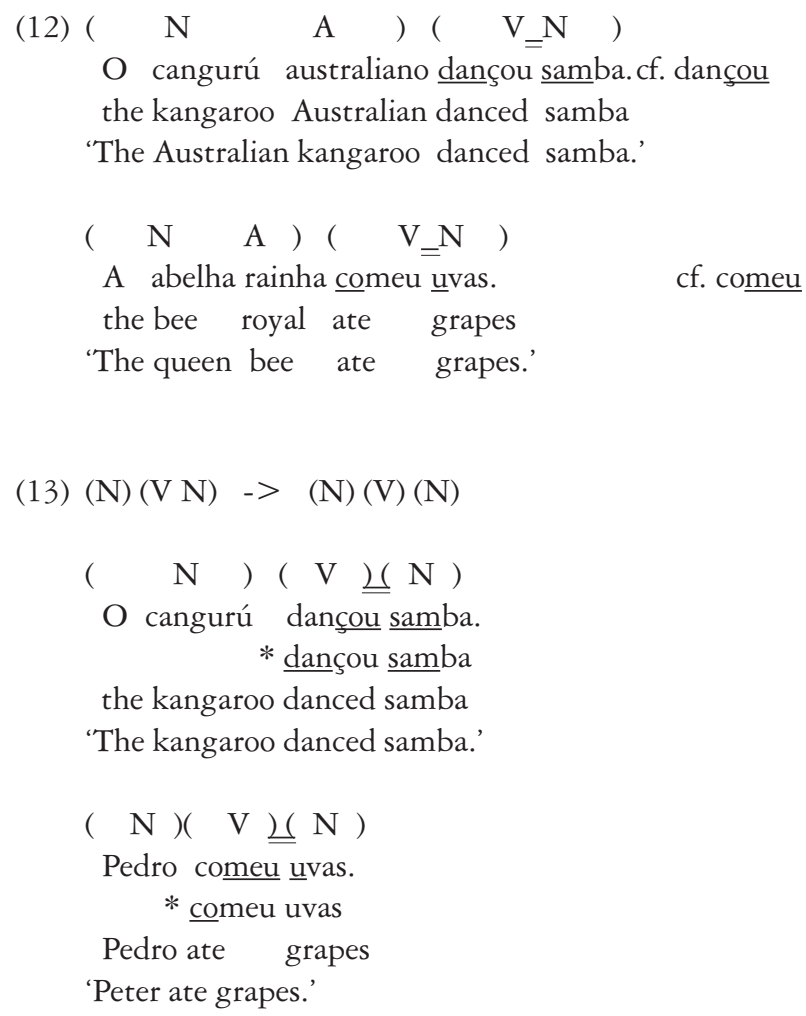

In (13), then, the non-uniform phrasing $1+2$ predicted by Align-XP, $\mathrm{R}$ is restructured to the uniform phrasing $1+1+1$, with $\mathrm{p}$-phrases of equal length.

A uniformity effect was also observed in the analysis of Italian phrasing in Ghini (1993). Ghini argues for a revision of the theory of p-phrase 
formation in Italian due to Nespor and Vogel (1986). In Ghini's proposal for Italian, Align-XP,R interacts with a number of eurythmic principles on possible p-phrases. Central to the analysis is the principle Uniformity and average weight, rendered in (14).

(14) Uniformity and average weight (Ghini 1993)

A string is ideally parsed into same length units; the average weight of the $\varnothing$ s depends on tempo: at an average rate of speech (moderato), a $\varnothing$ contains two phonological words; the number of Ws within a $\varnothing$ increases or decreases by one by speeding up or slowing down the rate of speech.

Ghini's evidence for eurythmic principles comes from structures in which longer sequences of prosodic words are not divided by Align-XP,R. Such strings are then broken up into smaller $\mathrm{p}$-phrases by the eurythmic principles. For example, a string of five prosodic words as in (15), unaffected by Align-XP,R, will be divided into p-phrases of a length of two prosodic words due to Uniformity and average weight. The uneven number five leads to a left-over prosodic word that has to form a p-phrase on its own. (15) shows phrasings with the shorter p-phrase in initial, medial, and final position. A further principle, punishing increasing length at the end of the string, rules out (15c), leaving the possible phrasings in (15a,b). At a faster rate of speech, longer p-phrases as in (16) are possible, where, again, increasing length at the end of the string is ruled out (16b).

(15) a. $2+1+2$ (Ho_mangiato dei_pasticcini $)_{\mathrm{P}}(\text { ripieni })_{\mathrm{P}}(\text { di_cioccolata amara })_{\mathrm{P}}$ b. $1+2+2$ (Ho_mangiato $)_{\mathrm{P}}(\text { dei_pasticcini ripieni })_{\mathrm{P}}(\text { di_cioccolata amara })_{\mathrm{P}}$ c. $2+2+1 *\left(\mathrm{Ho}_{-} \text {mangiato dei_pasticcini }\right)_{\mathrm{P}}$ (ripieni di_cioccolata $)_{\mathrm{P}}(\text { amara })_{\mathrm{P}}$ 'I have eaten the donuts filled with bittersweet chocolate.'

(16) a. $2+3$ (Ho_mangiato dei_pasticcini $)_{\mathrm{P}}(\text { ripieni di_cioccolata amara })_{\mathrm{P}}$
b. $3+2$

In Ghini's Italian data, the uniformity effect is thus tied to a length preference that depends on rate of speech. In BP, on the other hand, the uniformity effect does not seem to be tied to a length preference: At the same rate of speech, $2+2$ is acceptable, and $1+2$ as well as $2+1$ are restructured to $1+1+1$. If a length-preference of 1 prosodic word was crucially involved in BP, we would expect $2+2$ to restructure to $1+1+1+1$. If, on the other hand, a length-preference of 2 was crucially involved, $2+2$ 
would correctly remain unaffected, but we would expect that $1+2$ and $2+1$ remain unchanged. In a first approximation, we capture the Uniformity effect of BP with the first clause of Ghini's formulation in (14)-an effect of Uniformity that is independent of average weight.

(17) Uniformity: A string is ideally parsed into same length units.

We pause in our investigation of the phrasing to illustrate the eurythmic effect with some pitch-tracks we have obtained from one of our consultants. (18) shows a pitch-track of the sentence in (10), phrased (Café quente) ${ }_{P}$ (queima a $\left.\underline{\underline{\text { boca }}}\right)_{P}$ in our analysis. ${ }^{9}$ We believe that each word-stress is here associated with a tonal rise, and that the distinction between wordstress and phrasal stress is reflected in the size of the pitch-excursion in non-final positions: There is a higher rise in (18) on the phrasal stress on quente than on the preceding and following word-stresses.

(18) $(\text { Café quente })_{\mathrm{P}}\left(\underline{\underline{\text { queima a boca }}}{ }_{\mathrm{P}}\right.$

(19) shows a pitch-track for (11), phrased $(\text { cafế })_{P}\left(\right.$ quente $_{P}$ (queima) $_{P}$ in our analysis. Here, unlike in (18), the initial rise on café is not smaller than the rise on quente. This would seem to be the intonational reflexion of the phrasal stress on café in (19), owing to Uniformity, in contrast to the wordstress on café in (18). Note also that the position of stress seems to condition

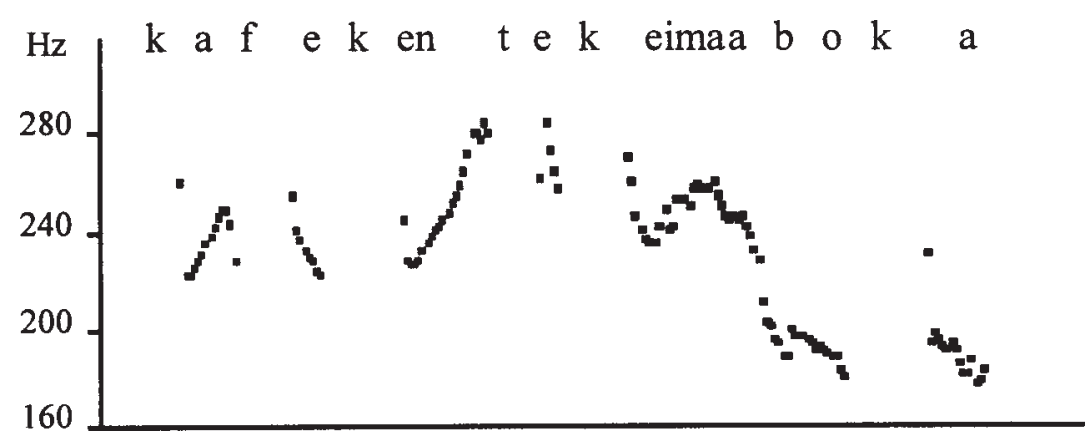

Figura 1: Entoação NAVN

9 The transcriptions are aligned with the aid of spectrograms, not included here. Much of the alignment between $\mathrm{f} 0$ and text can also be seen in the pitch-track from the interruptions of the f0track during the voiceless consonants. 
the timing of the rise, which ends with the first vowel of café in (18) but with the second vowel of café in (19), and thus in both cases with the end of the postulated strongest stress of the word. These remarks are very tentative. We have not studied these issues in any detail at this point.

(19) $(\text { café })_{\mathrm{P}}\left(\underline{\text { quente }}_{\mathrm{P}}\left(\underline{\text { queima }}_{\mathrm{P}}\right.\right.$

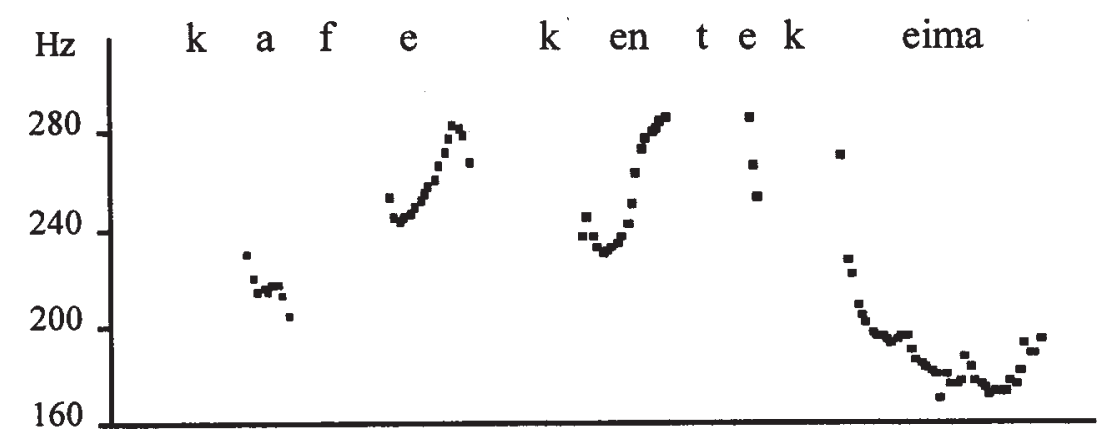

Figura 2: Entoação NAV

A pitch-track for the example in (4) above, phrased (café $)_{P}$ (queima $_{P}$, is shown in (20). Phrasal stress on café is again evidenced by a high rise late in the word.

(20) $(\text { café })_{\mathrm{p}}(\underline{\underline{\text { queima }}})_{\mathrm{P}}$

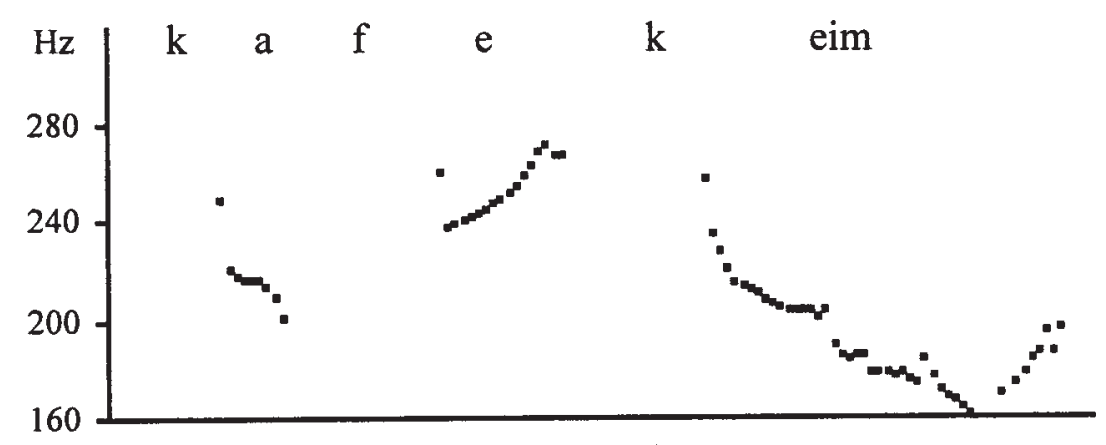

Figura 3: Entoação NV 


\section{A syntactic restriction on Uniformity}

In this section, we argue that Uniformity in fact only applies under limited syntactic conditions in BP, namely between the subject and the verb. This is stated in (22). We return to the bracketed condition on adjacency below.

(22) Subject and verb (if adjacent) are phrased in same length units.

Notice first that (22) is compatible with the examples discussed in the preceding section: In $(\mathrm{N} \mathrm{A})(\mathrm{V} \mathrm{N})$, subject and verb are both contained in p-phrases that are two prosodic words in length. On the other hand, in $(\mathrm{N}$ $\mathrm{A})(\mathrm{V})$ and in $(\mathrm{N})(\mathrm{V} \mathrm{N})$, subject and verb are members of $\mathrm{p}$-phrases with different prosodic length, one and two prosodic words, while the restructured $(\mathrm{N})(\mathrm{A})(\mathrm{V})$ and $(\mathrm{N})(\mathrm{V})(\mathrm{N})$ phrase both subject and verb in pphrases of equal length of one prosodic word.

We begin by illustrating the syntactic restriction on Uniformity with examples of the form (N A)(V XP)(YP), where XP and YP are maximal projections. The phrasing here is as predicted by Align-XP, R, and results in the prosodic pattern $2+2+1$. Crucially, the presence of a final short $\mathrm{p}$ phrase does not lead to a Uniformity effect in the rest of the string, which would amount to the uniform phrasing $1+1+1+1+1$. The phrasing $2+2+1$ is unexpected on the unrestricted formulation of Uniformity in (17), but follows from the restricted formulation in (22): Subject and verb are here both contained in p-phrases of length two. The final YP in these structures is neither part of the subject nor of the verb, and thus is not included in the restricted evaluation of Uniformity in (22).

The first such case is the one already discussed in (1)/(2) above, where $(\mathrm{N} \mathrm{A})(\mathrm{V} \mathrm{N})(\mathrm{Adv})$ is phrased as predicted by Align-XP,R, rather than restructured to $(\mathrm{N})(\mathrm{A})(\mathrm{V})(\mathrm{N})(\mathrm{Adv})$, given the obligatory presence of the final short p-phrase around the adverb.

A further case of this kind that involves an adverbial is the structure $(\mathrm{N} \mathrm{A})(\mathrm{V} \mathrm{Adv})(\mathrm{N})$, discussed in (9) above, where (9) gave evidence for the p-phrase boundary following the adverbial phrase. In (23), the application of stress-retraction within the subject (23a) and between the verb and the adverbial (23b) is evidence for the absence of p-phrase boundaries in this 
structure. Here again we see the absence of a Uniformity effect that the final short p-phrase would be expected to trigger by (17).

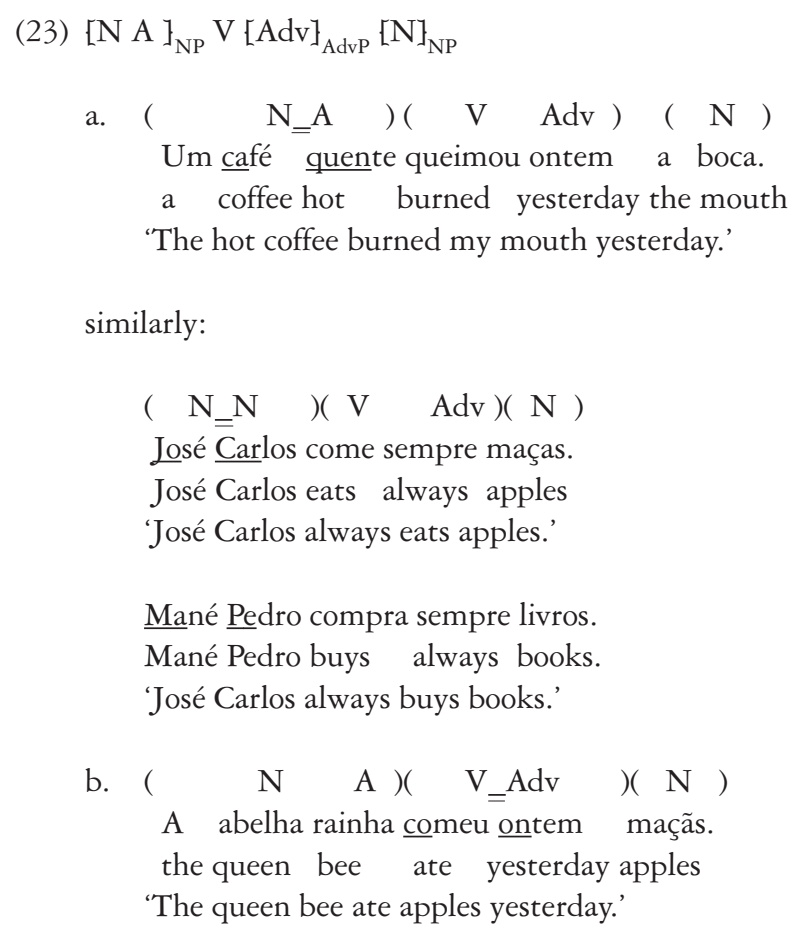

Given only (1)/2) and (23), one might wonder whether perhaps adverbials have a special status that might account for these exceptions to Uniformity: One might consider, for example, a derivation in which the adverbials are added late in the derivation (Lebeaux 1988, Chomsky 1995). As shown in (24), the phrasings in (30) and (23) could be derived by applying Align-XP and Uniformity before the adverbial is added to the structure (here the uniform $2+2$ would be assigned), and by later adding the adverbial and the p-phrase boundary at its right edge.

(24) Align-XP,R, Uniformity $(\mathrm{N} \mathrm{A})(\mathrm{V} \mathrm{N})$

$(\mathrm{N} \mathrm{A})(\mathrm{V} \mathrm{N})$

$\begin{array}{ll} & \text { Add AdvP, Align-XP,R } \\ -> & (\mathrm{N} \mathrm{A})(\mathrm{V} \mathrm{N}) \underline{(\mathrm{Adv})} \\ -> & (\mathrm{N} \mathrm{A})(\mathrm{V} \underline{\mathrm{Adv}})(\mathrm{N})\end{array}$

However, other examples suggest that the restriction on Uniformity is not limited to adverbials or non-selected constituents. Thus, (25) shows 
structures with two objects, where the same effect is observed: The final short p-phrase on the second object does not lead to a Uniformity effect that shortens the earlier p-phrases. ${ }^{10}$ Here the application of stress retraction between $\mathrm{N}$ and $\mathrm{A}$ in the subject (25a) and between $\mathrm{V}$ and $\mathrm{O} 1$ (25b) is evidence for the large p-phrasing earlier in this string. ${ }^{11}$

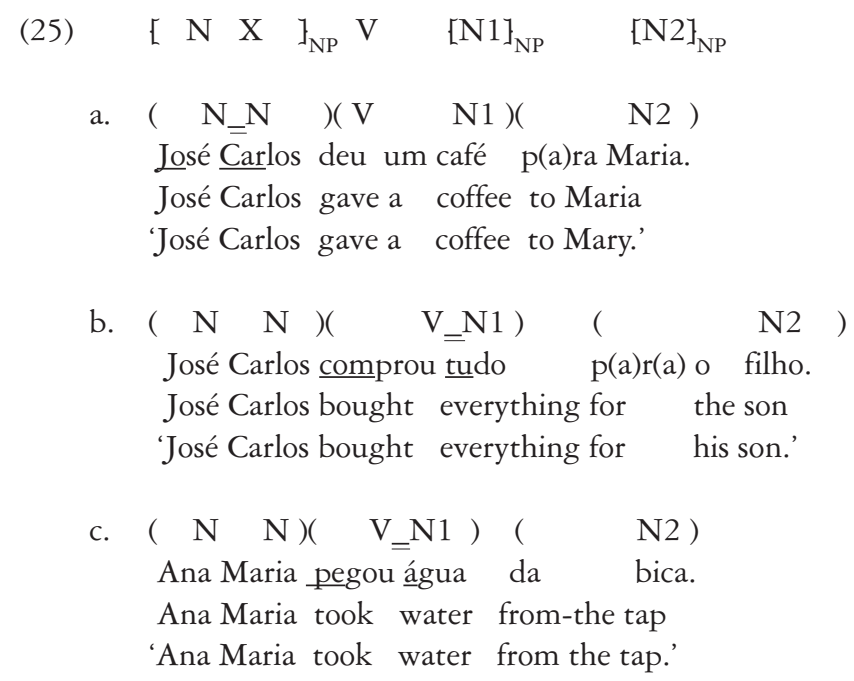

The restriction on Uniformity in (22) has a variety of effects beyond those involving structures of the form $(\mathrm{N} \mathrm{X})(\mathrm{V} \mathrm{XP})(\mathrm{YP})$. A striking effect of a different kind is shown in (26), where the verb is followed by a complex object. (26a) shows that there is a p-phrase boundary separating the subject and the verb and (26b) shows that verb phrases by itself. This is not predicted by Align-XP,R, and may be attributed to Uniformity: Following the short subject, a further short p-phrase containing only the verb is constructed. Crucially, the Uniformity effect does not propagate into the complex object. As shown by the application of stress retraction in (26b), $\mathrm{N}$ and $\mathrm{A}$ within the object are still phrased together.

10 The second objects here are PPs, and thus binary syntactically. However, we believe that there is no word-stress on the functional prepositions here, and that the second objects thus do not consist of two prosodic words.

11 Note that the preposition para undergoes vowel reduction in BP in a non-formal and nonemphatic speech. The reduced vowels are indicated by ( ) in our data. As mentioned before, an emphatic realization, where the preposition bears a primary stress and where it does not undergo reduction, interferes with phonological phrasing and it was avoided. 


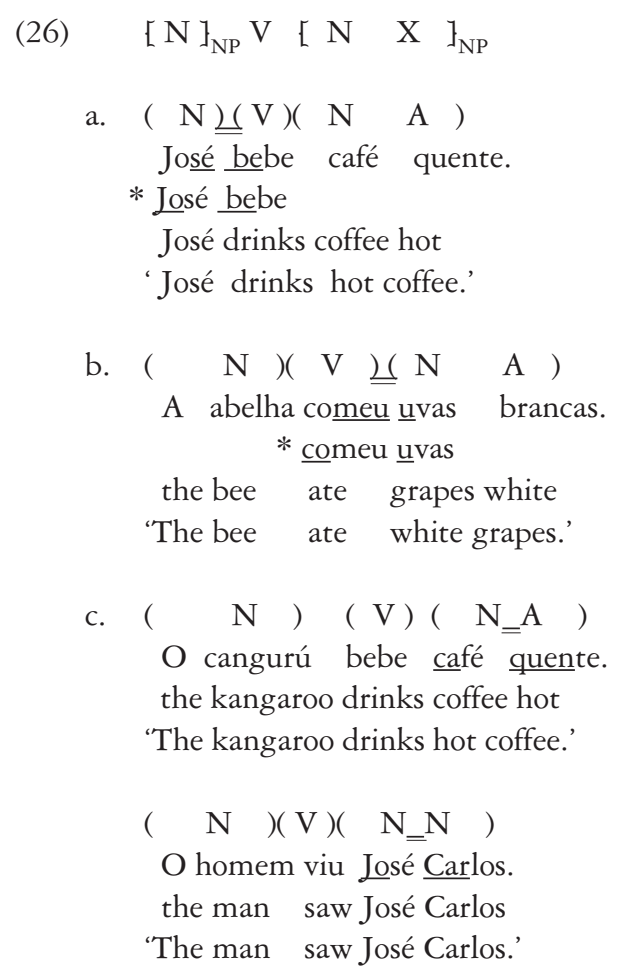

This pattern follows from restricted Uniformity in (22): The shortness of the subject requires a short p-phrase for the verb. However, the Uniformity effect is correctly predicted not to extend into the complex object by (22). Unrestricted Uniformity in (17) would here wrongly predict a phrasing of $1+1+1+1$, with the Uniformity effect extending into the complex object.

(26) is telling in a number of respects. First, it provides a further case that demonstrates that the limits of Uniformity cannot be attributed to the special status of adverbs. In the structure in (26), the failure of Uniformity to propagate concerns the object of a verb. Second, (26) shows that the failure of Uniformity to propagate can be observed both directions: In (30), (23), and (25), Uniformity effects fail to apply from right to left, but in (26) they fail to apply from left to right. Third, one might have pursued the intuition that Uniformity is strong enough to introduce one p-phrase boundary, as in the examples in (11) and (13) above, but that Uniformity is not strong enough to introduce multiple p-phrase boundaries, if that is what it would take to make the string uniform. Thus, one might have reasoned, in (30), (23), and (25), Uniformity does not introduce any 
additional boundaries, because one boundary would not be enough to achieve complete Uniformity. However, this would not carry over to (26). Here, too, the addition of two p-phrase boundaries would be required to transform the properly aligned $(\mathrm{N})(\mathrm{V} \mathrm{N} \mathrm{A})$ into a uniform phrasing. Unlike in the other cases, however, this does not lead to the absence of a Uniformity effect alltogether. Instead, Uniformity applies once, giving $(\mathrm{N})(\mathrm{V})(\mathrm{N}$ A). Finally, (26) allows us to discard another hypothesis about the earlier examples that is similar to the preceding hypothesis, though with a different idea at its core. Perhaps, one might reason, $2+2+1$ is preserved because of majority rule: since the longer p-phrases outnumber the shorter ones, perhaps the phrasing is accepted as an imperfect specimen with average length of 2, rather than treated as an imperfect specimen with average length 1 , to be restructured into a perfect one. Whatever the formalization of this idea, it would not explain why the Uniformity effect stops at the object in (26), even though the result is an imperfect specimen with average length 1 by majority rule.

The cases we have discussed so far that show the limits of Uniformity are schematically assembled in (27).

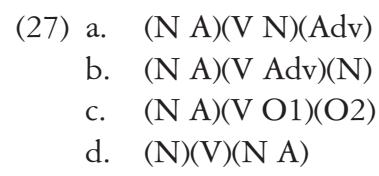

It was seen that these are captured in the syntactically restricted formulation of Uniformity in (22). However, these cases might alternatively be derived by a prosodic restriction on Uniformity: One might maintain that Uniformity applies only to the first two p-phrases of the string. Thus, in (27a.-c), the first two p-phrases have length two, so that no Uniformity effect due to the third shorter p-phrase is expected. In (27d), the prosodic restriction likewise makes the correct prediction: The initial short $\mathrm{p}$-phrase would still require the presence of one additional short $\mathrm{p}$-phrase following it, but would not insist on further short p-phrases after the first two of the string. This phrasing, too, could thus be correctly derived. Such an account would also correctly extend to the cases discussed in section 3 , where $2+2$ is accepted, while $2+1$ and $1+2$ are rejected (both beginning with two pphrases of unequal length). The result of rephrasing, on the other hand, in both cases $1+1+1$, would begin in two p-phrases of equal length. 
However, two additional cases in our data suggests that the syntactic restriction on Uniformity is empirically superior to the prosodic one. Consider first (28), a structure in which a short adverb intervenes between a long subject and a long VP. The impossibility of retraction in a. and b. establishes the presence of the p-phrase boundaries to the left and to the right of the adverb. These are predicted by Align-XP,R at the right edge of the subject and at the right edge of the adverbial phrase. As shown by the application of retraction in c. and d., no Uniformity effect emanates from the medial short p-phrase of the adverbial into either the preceding subject or the following VP.

(28) $(\mathrm{N} \mathrm{X})(\mathrm{Adv})(\mathrm{V} \mathrm{N})$

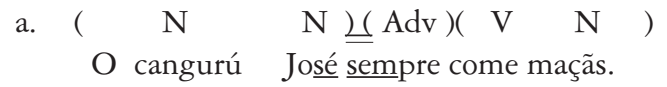

* Losé sempre

the kangaroo José always eats apples

'The kangaroo José always eats apples.'

b. $(\mathrm{N} \quad \mathrm{A})(\operatorname{Adv} \underline{\underline{N}} \mathrm{~N})$

A abelha rainha amanhã compra livros.

*amanhã compra

the royal bee tomorrow buys books

'The queen bee is buying books tomorrow.'

c. $\left(\quad \mathrm{N}_{=} \mathrm{A}\right)\left(\begin{array}{llll}\operatorname{Adv} & \mathrm{V} & \mathrm{N}\end{array}\right)$

Um café quente ontem queimou minha boca.

a coffee hot yesterday burned my mouth

'A hot coffee burned my mouth yesterday.'

d. $\left(\begin{array}{lllll}\quad \mathrm{N} & \mathrm{A} & )(\operatorname{Adv} & (\mathrm{V}=\mathrm{N}\end{array}\right)$

A abelha rainha ontem comeu uvvas.

the bee royal yesterday ate apples

'The queen bee ate apples yesterday.'

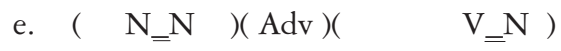

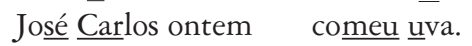

José Carlos yesterday ate grapes

'José Carlos ate grapes yesterday.'

If Uniformity applied to the first two p-phrases of the string but not elsewhere, (28) should show restructuring within the subject. This would 
be expected to be parallel to restructuring within the subject in (13), where $(\mathrm{N} \mathrm{A})(\mathrm{V})$ becomes $(\mathrm{N})(\mathrm{A})(\mathrm{V})$.

On the other hand, the syntactic restriction on Uniformity in (22) correctly predicts that the Uniformity effect does not propagate leftward or rightward from the medial adverbial in (28): Subject and verb are each contained in $\mathrm{p}$-phrases of length 2 , and the presence of the intervening adverbial is correctly predicted not to change this phrasing.

A further case that allows us to distinguish between the prosodic and the syntactic restriction on Uniformity is given in (29). Here the subject consists of two coordinated conjuncts, for a total length of four prosodic words. Align-XP,R predicts separate phrasing of the conjuncts. However, $\mathrm{N}$ and $\mathrm{A}$ within the first conjunct are also phrased separately, as evidenced by the blocking of stress retraction in $(29 a, b) .{ }^{12}$

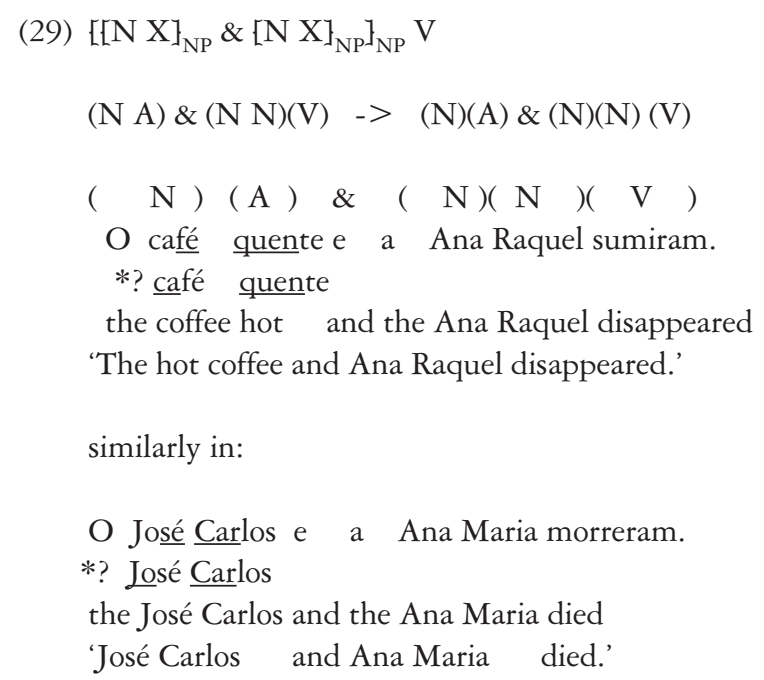

The phrasing $2+2+1$, derived by Align-XP,R, would wrongly be tolerated by the prosodic restriction on Uniformity, as this phrasing begins

\footnotetext{
12 Stress retraction in a coordinated subject was accepted by one of our consultants if retraction could be applied in both of the coordinated nominal phrases. That is, an example like $O$ café quente e o José Carlos sumiram 'The hot coffee and José Carlos disappeared' was accepted. We suspect interference from a possible parallelism requirement in the coordinated structure for this consultant, but will not pursue the matter here. The possibility of interference of course weakens the argument made on the basis of this construction.
} 
with two p-phrases of equal length. This prosodic restriction could thus not draw a distinction between (29), were $2+2+1$ is not tolerated, and the earlier cases in which the phrasing $2+2+1$ was tolerated. (22), however, correctly extends to the case at hand: As the verb is phrased in a short pphrase, uniformity of phrasing across subject and verb is achieved by assigning short $\mathrm{p}$-phrases across the subject as well. In the case at hand, this affects both conjuncts within the complex subject.

We have shown, then, that Uniformity does not apply in all cases in $\mathrm{BP}$, and that the restriction on its application is best captured by limiting its domain of application to subject and verb. Before concluding this section, we turn to the question whether subject and verb need to be adjacent for the Uniformity effect to apply across them. At issue is the distinction between (30a) and (30b).

(30) a. Subject and verb are phrased in same length units.

b. Subject and verb, if adjacent, are phrased in same length units.

Examples in which an adverb intervenes between subject and verb were already discussed in (28) above. Those examples, however, tested for whether Uniformity emanates from the intervening adverb into subject of VP, both of which were of length two. Now we are raising the question whether Uniformity can 'skip' an intervening adverb when operating between subject and verb. Consider the test structure in (31). If Uniformity applies across an adverb that intervenes between subject and verb, the short subject should here trigger a Uniformity effect in the VP, blocking retraction between the verb and the object.

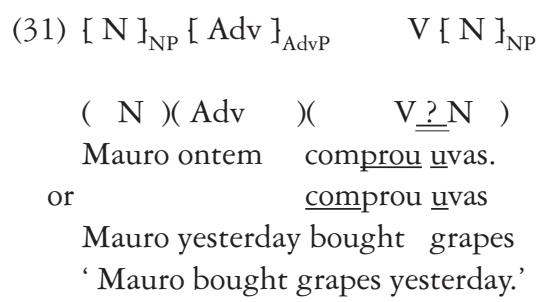

The judgements we obtained on cases like this did not converge on a clear result. Tentatively, we interpret this absence of a clear preference in this structure as optionality, such that Uniformity holds between subject 
and verb when they are adjacent, and optionally holds between them otherwise.

\section{Remarks on the Role of Focus}

In BP, narrow focus on a word blocks stress-retraction on that word. We illustrate this with a focused rendition of an example in (12) above. Recall that the default phrasing of this example was $(\mathrm{N} \mathrm{A})(\mathrm{V} \mathrm{N})$. Evidence for the joint phrasing of verb and object in (12) is the stress retraction on the verb, given stress clash. However, when narrow focus is placed on the verb, as in (32), stress retraction does not apply to the verb.

(32) A abelha rainha comeu ou deu as uvas?

'Did the queen bee eat grapes or give grapes away?'

A abelha rainha comeu uvvas

[ foc ]

* comeu uvas

the bee royal ate grapes

'The queen bee ate grapes.'

Our account for why focus blocks stress retraction rests on Nespor and Vogel (1989)'s proposal on the interaction of stress retraction with pphrases, introduced in section 1 above: the presence of stronger stress at the end of the p-phrase blocks the remedy of stress-clash. This account is straightforwardly extended to focus: In BP, as in many other languages, narrow focus attracts stress (see Jackendoff (1972) for English). With the presence of $\mathrm{p}$-phrase stress on the focused element, retraction on the focused element is blocked simply by the stress on the focused element. Thus,

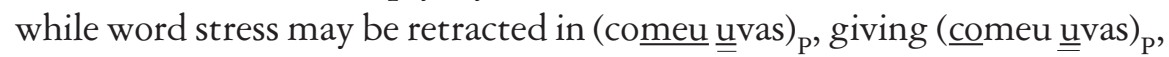
focus on the verb will lead to phrasal or higher stress, blocking retraction in comeu.

A question arises as to whether the stress on the focus simply shifts the phrasal stress to the verb, leaving the p-phrasing intact, as in (comeu uvas) ${ }_{\mathrm{P}}$, or whether it adds stress, leaving the final phrasal stress on the object intact, perhaps giving (comeu $\underline{\underline{\text { uvvas}}}{ }_{\mathrm{P}}$. Since, however, prosodic constituents and prominence are often thought to be in a biunique relation 
(see the Faithfulness Condition of Halle and Vergnaud (1987), Hayes (1995)), the latter scenario would lead us to expect two separate p-phrases for verb and object, thus (comeu $)_{\mathrm{p}}(\underline{\underline{\mathrm{u}}} \mathrm{vas})_{\mathrm{P}}$. This latter phrasing might also be derived if BP, like a number of other languages, inserts p-phrase boundaries to the right of a focused element. ${ }^{13}$ The differences are testable in BP, as the different phrasings would interact differently with the Uniformity effect discussed above. Consider (33). Here again we focus the verb in a structure otherwise phrased $(\mathrm{N} \mathrm{A})(\mathrm{V} N)$. In this case, however, we test for retraction within the subject, between $\mathrm{N}$ and $\mathrm{A}$. In (10) above, the sentence used in (33) was tested without narrow focus. There, stress retraction applies within the subject, giving evidence for the joint phrasing of $\mathrm{N}$ and $\mathrm{A}$ in the subject. Interestingly, this retraction within the subject is blocked in (33). This is evidence for the presence of a p-phrase edge between $\mathrm{N}$ and $\mathrm{A}$ within the subject, when the verb is in narrow focus.

(33) O que café quente faz com a boca?

'What does hot coffee do to one's mouth?'

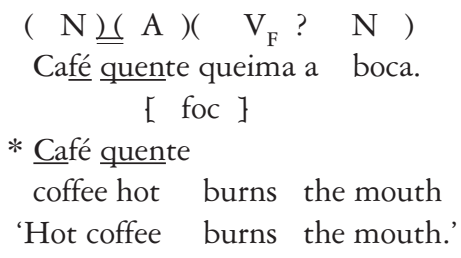

We attribute this change to Uniformity here, and conclude that focus changes the prosodic structure among verb and object in such a way as to trigger a Uniformity effect leftward into the subject. This suggests that the focus does not simply move the stress to an earlier position, turning (queima a $\underline{\underline{\text { boca }}})_{\mathrm{P}}$ into (queima a boca) $)_{\mathrm{P}}$, as the still binary p-phrase could then not give rise to a Uniformity effect. Instead, it seems that the resulting phrasing is (queima) $(\text { (a boca })_{\mathrm{P}}$, where the unary p-phrases apparently forced by the focus then give rise to the Uniformity effect that leads to splitting of the subject. This result is compatible with the intuitive assessment of

13 See, for example, Hayes and Lahiri (1991) for Bengali, Kanerva (1989, 1990), and Truckenbrodt (1999) for Chichew $\$$ a. For a proposal to derive the insertion of the edge next to the focus from the assignment of prominence on the focus, see Truckenbrodt (1995). 
these focused structures, in which there is stress on the focused verb, followed by another beat of stress on the object.

We conclude the section on focus with a remark on the nature of the stress retraction judgements, in which focus seems to us to play a role. In the cases in which stress retraction is normally preferred, stress retraction is never literally obligatory. Retraction can always be avoided by placing special emphasis on the otherwise retracting element. This is not unexpected, given the preceding discussion, if such special emphasis is in fact focus (or a related means of putting phrasal stress on the element in question): With the presence of phrasal stress on the otherwise retracting element, retraction is blocked in the account of Nespor and Vogel (1989), applied here to BP. ${ }^{14}$

\section{Conclusion}

In summary, our investigation of BP phrasing in terms of stress retraction lead us to postulate right-alignment of syntactic and phonological phrases, as well as a eurythmic effect of Uniformity. The Uniformity effect was argued to be independent of a prosodic length-preference, and to be restricted to the p-phrases overlapping with the subject and the verb of the sentence.

E-mail: sandalo@iel.unicamp.br Recebido em outubro de 2001 Aprovado em agosto de 2002

\footnotetext{
14 On the other hand, in the cases in which stress retraction is blocked for independent reasons, such as by Align-XP, R or by Uniformity in the account above, focus on the retracting element does not seem to affect the judgements. This is as expected, if the main effect of focus is to add stress, and thus possibly block retraction: Where retraction is blocked on independent grounds, focus will not change that picture.
} 


\section{REFERENCES}

Abousaly, Elaine S. Ferreira 1997. Resolução de choques de acento no português brasileiro. Master thesis, Universidade Estadual de Campinas (UNICAMP), Brazil.

Bisol, Leda 1992. O acento: Duas alternativas de análise. Ms., Pontifícia Universidade Católica do Rio Grande do Sul, Brazil.

CHen, Matthew Y. (1987). The syntax of Xiamen tone sandhi. Phonology Yearbook 4:109-149.

Cномsкy, Noam 1995. The minimalist program. Cambridge, Mass.: MIT Press.

Costa, João 1998. Word order variation. Doctoral dissertation, Holland Institute of Generative Linguistics.

DE LACY, Paul 1999. Higher prosody in Maori. Ms., University of Massachusetts, Amherst.

Galves, Charlotte 1989. O objeto nulo no português brasileiro: percurso de uma pesquisa". Cadernos de Estudos Lingüísticos 17. Universidade Estadual de Campinas (UNICAMP), Brazil.

Frota, Sónia 1998. Prosody and focus in European Portuguese. Doctoral dissertation, Universidade de Lisboa.

Frota, Sónia, and Marina Vigário 2000a. On the correlates of rhythmic distinctions: The European/Brazilian Portuguese case. Ms., Universidade de Lisboa, and Universidade do Minho, Braga, Portugal.

Frota, Sónia, and Marina Vigário 2000b. Aspectos de prosódia comparada: Ritmo e entoação no pe e no pb. Ms., Universidade de Lisboa, and Universidade do Minho, Braga, Portugal.

GHINI, Mirco 1993. Ø-formation in Italian: A new proposal. In Carrie Dyck (ed.), Toronto Working Papers in Linguistics vol. 12, no. 2. Department of Linguistics, University of Toronto, pp. 41-78.

Gussenhoven, Carlos 1991. The English rhythm rule as an accent deletion rule. Phonology 8(1):1-35.

Halle, Morris, and Jean-Roger Vergnaud 1987. An essay on stress. Cambridge, Mass.: MIT Press.

HAYEs, Bruce 1984. The phonology of rhythm in English. Linguistic Inquiry 15(1):33-74.

Hayes, Bruce 1989. The prosodic hierarchy in meter. In Paul Kiparsky and G. Youmans (eds.), Rhythm and meter, Orlando: Academic Press.

Hayes, Bruce 1995. Metrical stress theory: Principles and case studies. Chicago: The University of Chicago Press. 
Hayes, Bruce, and S. Pupple 1985. On the rhythm rule in Polish. In Harry van der Hulst and Norval Smith (eds.), Advances in nonlinear phonology, Dordrecht: Foris, pp. 59-81.

Hayes, Bruce, and Aditi Lahiri 1991. Bengali intonational phonology. Natural Language E Linguistic Theory 9(1):47-96.

HsiaO, Franny 2001. Tonal domains are stress domains in Taiwaneseevidence from focus. Ms., Massachusetts Institute of Technology.

JACKENDOFF, Ray S. 1972. Semantic interpretation in generative grammar. Cambridge, Mass.: MIT Press.

Kanerva, Jonni M. 1989. Focus and phrasing in Chichew\$a phonology. Doctoral dissertation, Stanford University.

Kanerva, Jonni M. 1990. Focus on phonological phrases in Chichew\$a. In Sharon Inkelas and Draga Zec (eds.), The phonology-syntax connection, Chicago: The University of Chicago Press, pp. 145-161.

Lebeaux, David 1988. Language acquisition and the form of the grammar. Doctoral dissertation, University of Massachusetts.

Liberman, Mark, and Alan Prince 1977. On stress and linguistic rhythm. Linguistic Inquiry 8(2):249-336.

Major, Roy C. 1985. Stress-timing in Brazilian Portuguese. Journal of Phonetics 9:343-351.

McCarthy, John, and Alan Prince 1993. Generalized alignment. In Geert Booij and Jaap van Marle (eds.), Yearbook of morphology 1993, Dordrecht: Kluwer, pp. 79-153.

Nespor, Marina 1990. On the separation of prosodic and rhythmic phonology. In Sharon Inkelas and Draga Zec (eds.), The phonologysyntax connection, Chicago: The University of Chicago Press, pp. 243258.

Nespor, Marina 1999. Stress domains. In Harry van der Hulst (ed.), Word prosodic systems in the langanges of Europe, Berlin: Mouton de Gruyter, pp. 117-159.

NesPor, Marina, and Irene Vogel 1979. Clash avoidance in Italian. Linguistic Inquiry 10(3):467-482.

NesPor, Marina, and Irene Vogel 1986. Prosodic phonology. Dordrecht: Foris.

Nespor, Marina, and Irene Vogel 1989. On clashes and lapses. Phonology 6(1):69-116.

Prince, Alan, and Paul Smolensky 1993. Optimality Theory: Constraint interaction in generative grammar. Ms., Rutgers University and University of Colorado, Boulder. 
SANTOS, Raquel Santana 2002. Categorias sintáticas vazias e retração de acento em português brasileiro. DELTA 18:1, pp. 67-86.

SELKIRK, Elisabeth 1986. On derived domains in sentence phonology. Phonology Yearbook 3:371-405.

SELKIRK, Elisabeth 1995. The prosodic structure of function words. In Jill Beckman, Laura Walsh Dickey and Suzanne Urbanczyk (eds.), Papers in Optimality Theory. University of Massachusetts Occasional Papers 18, Amherst, Mass: GLSA, pp. 439-469.

SelkIRK, Elisabeth, and Tong Shen 1990. Prosodic domains in Shanghai Chinese. In Sharon Inkelas and Draga Zec (eds.), The phonology-syntax connection, Chicago: The University of Chicago Press, pp. 313-337.

SelKirk, Elisabeth, and Koichi Tateishi 1991. Syntax and downstep in Japanese. In Carol Georgopolous and Roberta Ishihara (eds.), Interdisciplinary approaches to language: Essays in honor of $s-y$ Kuroda, Dordrecht: Kluwer, pp. 519-543.

Shattuck-Hufnagel, Stefanie, Mari Ostendorf, and Ken Ross 1994. Stress shift and early pitch accent placement in lexical items in American English. Journal of Phonetics 22:357-388.

TRuCKenbrodt, Hubert 1995. Phonological phrases: Their relation to syntax, focus, and prominence. Doctoral dissertation, Massachusetts Institute of Technology.

Truckenbrodt, Hubert 1999. On the relation between syntactic phrases and phonological phrases. Linguistic Inquiry 30(2):219-255.

VIsch, Ellis 1989. A metrical theory of rhythmic stress phenomena. Doctoral dissertation, University of Utrecht. 